\title{
A.G. Elayi, M. Blet-Lemarquand, J. Elayi, F. Duval. Analyses of the Composition of the Coinage of Arwad (5th-4th cent. BC)
}

\section{Astrid Nunn}

\section{(2) OpenEdition}

Journals

Édition électronique

URL : http://journals.openedition.org/abstractairanica/41606

DOI : 10.4000/abstractairanica.41606

ISSN : 1961-960X

Éditeur :

CNRS (UMR 7528 Mondes iraniens et indiens), Éditions de l'IFRI

\section{Référence électronique}

Astrid Nunn, «A.G. Elayi, M. Blet-Lemarquand, J. Elayi, F. Duval. Analyses of the Composition of the Coinage of Arwad (5th-4th cent. BC) », Abstracta Iranica [En ligne], Volume 34-35-36 | 2017, document 52, mis en ligne le 15 juillet 2016, consulté le 05 octobre 2020. URL : http://journals.openedition.org/ abstractairanica/41606 ; DOI : https://doi.org/10.4000/abstractairanica.41606

Ce document a été généré automatiquement le 5 octobre 2020.

Tous droits réservés 


\title{
A.G. Elayi, M. Blet-Lemarquand, J. Elayi, F. Duval. Analyses of the Composition of the Coinage of Arwad (5th-4th cent. BC)
}

\author{
Astrid Nunn
}

\section{RÉFÉRENCE}

A.G. Elayi, M. Blet-Lemarquand, J. Elayi, F. Duval. « Analyses of the Composition of the Coinage of Arwad (5th-4th cent. BC) ». Trans., 42, 2012, p. 129-140.

1 Une étude approfondie des monnaies d'Arwad manque encore parmi les publications de A.G. et J. Elayi. Ont été sélectionnées 35 monnaies conservées au Cabinet des Médailles de la Bibliothèque Nationale de France à Paris. Parce qu'elles contiennent plus de plomb et moins d'argent, leur composition métallique diffère de celle des monnaies de Sidon, Tyr et Byblos. La quantité d'argent évolue selon l'histoire particulière d'Arwad, pourvoyeuse de la flotte à l'Empire perse.

\section{AUTEURS}

ASTRID NUNN

Université de Munich 